\title{
CRYOPRESERVATION OF SEMEN OF MITHUN AND SIRI BULLS
}

\author{
P. Dorji ${ }^{*}$, V. Pattarajinda ${ }^{2}$, T. Vongprolub ${ }^{2}$ \\ ${ }^{1}$ College of Natural Resources, Royal University of Bhutan \\ ${ }^{2}$ Department of Animal Science, Faculty of Agricultre, Khon Kaen University, Thailand
}

\begin{abstract}
The objective of the study was to assess the semen characteristics of Jersey, Mithun and Siri breeds of bulls and to compare the suitability of Tris Eggyolk Citrate and commercial soya lecithin based BIOXcell extenders for cryopreservation of semen from the these breeds of bulls. The mean semen volume was $4.55 \pm 1.57,4.86 \pm 1.33$ and $4.83 \pm 1.72 \mathrm{ml}$ in Jersey, Mithun and Siri bulls, respectively. Mean mass activity of 3, mean initial motility of $78.0 \pm 4.22,80 \pm 4.47$ and $78.33 \pm 4.08 \%$, mean sperm concentration of $1416 \pm 484.19,1530.91 \pm 517.41,1122.83 \pm 293.68 \times 10^{6}$ and mean livability of $69.20 \pm 6.81,70.45 \pm 8.42$, $76.67 \pm 8.17 \%$ was found in Jersey, Mithun and Siri bulls, respectively. There is no significant difference in all above mentioned variables among the breeds. The post-thaw motility of semen cryopreserved in Tris Eggyolk Citrate extender was found to be $45.50 \pm 4.38,46.82 \pm 6.81$ and $47.50 \pm 8.22 \%$ in Jersey, Mithun and Siri bulls, respectively. Whereas in BIOXcell extender, it was $45.50 \pm 5.99,46.36 \pm 5.05$ and $49.17 \pm 5.85 \%$ in Jersey, Mithun and Siri bulls, respectively. Similarly, the plasma membrane integrity of thawed spermatozoa in Tris eggyolk extender was $17.50 \pm 2.32,21.00 \pm 3.12$ and $21.58 \pm 3.83 \%$ in Jersey, Mithun and Siri bulls, respectively. Whereas in BIOXcell extender, it was found to be 20.45 $\pm 2.86,20.86 \pm 2.281$ and $22.33 \pm 3.24 \%$ in Jersey, Mithun and Siri bulls, respectively. No significant difference ( $p>0.05)$ was observed in post-thaw motility as well as in plasma membrane integrity between extenders and between breeds, and there was no significant effect $(p>0.05)$ of breed $x$ extender interaction. It can be concluded that the semen characteristics of Siri and Mithun bulls fall with the range established for other breeds of bulls. Furthermore, both Tris eggyolk and BIOXcell extenders are equally suitable for the cryopreservation of semen from these three breeds of Bulls.
\end{abstract}

Key words: Mithun bull, Semen characteristics, Semen cryopreservation, Siri bull

\section{INTRODUCTION}

The advent of technology such as artificial insemination (AI) and semen cryo-preservation has vastly increased the utility and the contribution of the bulls with high genetic merits. For AI, production of quality semen is of primary importance. The major cause of variation in semen quality is the environment (Foote, 1978). Quality of semen is determined by a combination of factors operating at two levels; at the level of the bull, conditions such as nutrition and temperature are considered to exert important influence on bull performance and semen quality while at the level of the spermatozoa, environment relates to those conditions to which the spermatozoa are exposed after ejaculation and in the processes of cryopreservation.

The series of drastic changes in their physical and chemical environment during the process of cooling, freezing and thawing can cause damage to up to $50 \%$ of the spermatozoa (Watson, 2000). The primary site of cryo-injury to spermatozoa is in the plasma membrane (Parks and Graham, 1992), which are attributed to membrane alterations induced by phase transitions that occur when membranes are cooled (Hammerstedt et al., 1990; Woelders, 1997; Watson, 2000; Medeiros et al., 2002), mechanical stress on cell membranes due to osmotic stress and temperature changes during freezing and thawing (Curry and Watson, 1994; Holt, 2000; Morris et al., 2007), increases in lipid peroxidation of the membrane induced by reactive oxygen species (ROS) (Alvarez and Storey, 1992; Meyers, 2005) and intracellular ice crystallization during cryopreservation (Mazur, 1984). The processes induce certain detrimental effects, in terms of sperm structure, biochemical and functional damage, resulting in a reduction of sperm motility, membrane integrity and fertilizing ability (Salamon and Maxwell, 2000). Therefore, the composition of extender and suitable cryoprotectants are important factors for successful semen cryopreservation (Hammerstedt et al., 1990; Curry et al., 1994).

Currently, egg yolk is an important constituent of extenders for cryopreservation of semen of domestic animals. This cryoprotective property of eggyolk is attributed to the phospholipids, cholesterol and low density

*Corresponding e-mail address: pdorji010@yahoo.com

Copyright (c) 2014 Bangladesh Society for Veterinary Medicine

All rights reserved 0303/2014 


\section{P. Dorji and others}

lipoproteins in egg yolk (Pace and Graham, 1974; Watson, 1976). The most commonly used egg yolk in extenders for cryopreservation of sperm is from chicken because of its wide availability. However, three main disadvantages work against the use of egg yolk in semen extenders; the wide variability in their composition, the risk of microbiological contamination and disease transmission, and interference in the microscopic examination attributed to the greater viscosity and the presence of particulate debris in extenders (Vishwanath and Shannon (2000). This has led to the search for extenders free of ingredients of animal origin. Lecithin from soy beans has been used successfully for semen cryopreservation of bull (Thun et al., 2002; Amirat et al., 2005; Muiño et al., 2007), ram (Forouzanfar et al., 2010) and dog semen (Beccaglia et al., 2009). BIOXcell (Gil et al., 2003a,b; Hansen et al., 2005; Stradaioli et al., 2007; Celeghini et al., 2008) has been used for the cryopreservation of bovine, caprine and ovine semen elsewhere.

Furthermore, semen from different breeds and species has different characteristics and physiology and therefore may respond differently to different cryopreservation methods including extenders. Moreover, there have been no studies on cryopreservation of semen of Siri and Mithun bulls. Thus, the objective of this study was to compare the effect of Tris eggyolk extender and commercial soya lecithin based extender (BIOXcell) on the freezability and post-thaw sperm quality of semen from these bulls.

\section{MATERIALS AND METHODS}

Animal

The experiment was conducted during the months of June to September, 2013. Bulls $(n=2)$ of three breeds, namely Siri, Mithun and Jersey of 5-6 years of age maintained at the National Dairy Development Centre used for semen collection for AI were used for the study. The bulls were offered a daily diet consisting of $3 \mathrm{~kg}$ concentrate mixture, $100 \mathrm{~g}$ of gram and adlibitum green grasses. The Semen laboratory is located at an altitude of around $2500 \mathrm{~m}$ above msl with an average ambient temperature of around $21^{\circ} \mathrm{C}$.

\section{Experimental Design and treatments}

The experiment was conducted with a Completely Randomized Block Design with breed as block and two animals in each block. Five ejaculates were collected from each bull of the 3 breeds and each ejaculate was divided into 2 aliquots, and assigned to two treatments. Treatment 1 and Treatment 2 consist of extending the semen with Tris-yolk citrate and commercial soya lecithin-BIOXcell extenders, respectively.

\section{Semen Collection and evaluation}

Semen was collected once a week from each bull using artificial vagina. The collection tube containing the semen is transferred to a water bath maintained at $35-37^{\circ} \mathrm{C}$ and subjected to macroscopic and microscopic evaluation. The volume, colour and consistency were recorded. Mass activity was graded according to Roberts (1971). Initial progressive motility was recorded as an aggregate of the visual assessment by two experienced persons. Semen was stained with Eosin-Nigrosin stain to assess sperm viability and morphological abnormality. Sperm concentration was measured using a haemocytometer as described by Henery (1991).

\section{Preparation of Extender and semen dilution}

The extenders were freshly prepared just before dilution. Tris-eggyolk extender was prepared by dissolving $3.025 \mathrm{~g}$ Tris buffer, $1.67 \mathrm{~g}$ citric acid and $1.25 \mathrm{~g}$ fructose in $50 \mathrm{ml}$ of distilled water by stirring after which the volume was adjusted to $73 \mathrm{ml}$ with distilled water. To this, $20 \mathrm{ml}$ of sterilized eggyolk was added and the solution is then centrifuged and divided into two parts; Part A $(50 \mathrm{ml})$ and Part B (43 ml). Part A was warmed to $37^{\circ} \mathrm{C}$ while to Part $\mathrm{B}, 7 \mathrm{ml}$ Glycerol was added, thoroughly mixed by heating and stirring, and cooled to $5{ }^{\circ} \mathrm{C}$. BIOXcell $^{\mathrm{TM}}$ extender was prepared by warming the $\mathrm{BIOXcell}$ solution to $34^{\circ} \mathrm{C}$ for 10 min and diluted 4 times the volume of the BIOXcell solution with sterile distilled water kept at $34^{\circ} \mathrm{C}$. The extender was then maintained at $34^{0} \mathrm{C}$. Semen samples showing normal characteristics of motility $(>70 \%)$, morphology and concentration $\left(>500 \times 10^{6} / \mathrm{ml}\right)$ were divided into 2 equal aliquots and diluted to obtain spermatozoa concentration of $20 \times 10^{6}$ per straw. One aliquot was extended with Tris-citrate egg yolk citrate extender in two steps. First dilution was carried out using solution A at $37^{\circ} \mathrm{C}$ and gradually cooled from $37^{\circ} \mathrm{C}$ to $5^{\circ} \mathrm{C}$ over $120 \mathrm{~min}$ in a biological freezer. The second dilution was made when the semen was cooled to $5^{0} \mathrm{C}$. Solution B maintained at $5^{0} \mathrm{C}$ was added. The 
other aliquot was extended with BIOXcell extender in a single step within $10 \mathrm{~min}$ of collection. Then the diluted semen was kept at $5^{0} \mathrm{C}$ for about $4 \mathrm{~h}$ for glycerol equilibration.

\section{Semen freezing and thawing}

After equilibration, the semen was loaded into $0.25 \mathrm{ml}$ straw with the help of straw filling and sealing machine after which they were placed in a liquid nitrogen ( $\mathrm{LN}$ ) cooling tank to vapour cool to $-85^{\circ} \mathrm{C}$ in $10 \mathrm{~min}$. When the temperature reached to $-85^{\circ} \mathrm{C}$, the straws were plunged into $\mathrm{LN}$ and stored. After storage for a week in $\mathrm{LN} 10$ semen straws were thawed at $37^{\circ} \mathrm{C}$ for $30-60$ seconds and examined under microscope at x40 magnification for post-thaw motility.

\section{Assessment of membrane integrity}

The combination of hypo osmotic swelling (HOS) test and Eosin Nigrosin (EN) staining method described by Moreno et al. (2011) was used to assess the membrane integrity of spermtozoa. For this, $0.1 \mathrm{ml}$ of thawed semen was mixed with $1.0 \mathrm{ml}$ hyposmotic solution $(150 \mathrm{mOsm} / \mathrm{mL})$ consisting of sodium citrate $(1.47 \mathrm{~g} / 100 \mathrm{~mL})$ and fructose $(2.7 \mathrm{~g} / 100 \mathrm{~mL})$, and incubated at $37^{\circ} \mathrm{C}$ for $30 \mathrm{~min}$. After incubation, slides were prepared from each sample by placing $10 \mu \mathrm{l}$ of semen on a glass slide followed by mixing with $10 \mu \mathrm{l}$ of EN staining solution. The staining of sperm head and the swelling response of sperm tail irrespective of the types of tail coiling from type $b$ to $g$ (presence of a swollen area at the tip of the tail (b-d), a hairpin curvature of the tail (c-e), a shortened and thickened tail (f), or a swollen area that partly or completely enveloped the curved tail of the spermatozoon (d, e \& g)) as described by Jeyendran et al. (1984) was determined. The type IV spermatozoa (head white (EN -ve) and Tail-swollen (HOS +ve)) as described by Zhu and Liu (2000) representing the spermatozoa with intact membrane in both the head and tail was recorded.

\section{Statistical analysis}

Data were analyzed using the SAS 9.1 statistical software package and expressed as the mean and standard deviation. The GLM procedure was used to test the difference in the mean semen characteristics between breeds and post-thaw semen quality between different treatments at a significance level of $\mathrm{P}<0.05$. Pearson's correlation coefficient test was used to investigate the correlation between initial motility and livability with post thaw motility and plasma membrane integrity.

\section{RESULTS}

\section{Semen Characteristics of different breeds of Bulls}

The semen characteristics of three different breeds of bulls, namely Jersey, Mithun and Siri were compared. The colour of semen was white and creamy with normal appearance and mean morphological abnormalities was $12.02 \pm 6.71 \%$ in all the bulls. The mean semen volume, initial motility, concentration and livability of the three breeds of bull are shown in Table 1. Mithun and Siri bulls had slightly higher volume of semen while Mithun had slightly higher initial motility and concentration, and Siri had slightly higher livability than Mithun and Jersey. However, there was no significant difference $(\mathrm{p}>0.05)$ in all above mentioned variables among the breeds.

Table 1. Semen Characteristics of different breeds of Bulls

\begin{tabular}{lllll}
\hline Breed of Bull & Volume $(\mathrm{ml})$ & Initial Motility $(\%)$ & Concentration $\left(\mathrm{x} 10^{6}\right)$ & Livability $(\%)$ \\
\hline Jersey $(\mathrm{n}=2)$ & $4.55 \pm 1.57^{\mathrm{a}}(2.5-7.0)$ & $78.0 \pm 4.22^{\mathrm{b}}(70-80)$ & $1416 \pm 484.19^{\mathrm{c}}(840-$ & $69.20 \pm 6.81^{\mathrm{d}}(55-$ \\
& & & $2540)$ & $77)$ \\
Mithun $(\mathrm{n}=2)$ & $4.86 \pm 1.33^{\mathrm{a}}(3.0-7.0)$ & $80 \pm 4.47^{\mathrm{b}}(70.0-90.0)$ & $1530.91 \pm 517.41^{\mathrm{c}}$ & $70.45 \pm 8.42^{\mathrm{d}}(50-$ \\
& & & $(1030-2680)$ & $80)$ \\
Siri $(\mathrm{n}=2)$ & $4.83 \pm 1.72^{\mathrm{a}}(3-7)$ & $78.33 \pm 4.08^{\mathrm{b}}(70-80)$ & $1122.83 \pm 293.68^{\mathrm{c}}$ & $76.67 \pm 8.17^{\mathrm{d}}(70-$ \\
& & & $(870-1667)$ & $90)$ \\
\hline
\end{tabular}

Figures in main column with similar superscript are not significantly different at $p>0.05$. 


\section{P. Dorji and others}

\section{Post-thaw motility}

The same semen samples from above were frozen using two types of semen extenders, namely Tris Eggyolk citrate and a soy lecithin based commercial extender BIOXcell to assess the post thaw semen quality. The post thaw motility and plasma membrane integrity in the two extenders in different breeds are shown in Table 2 . The aggregate mean post-thaw motility and plasma membrane integrity for all the semen samples from all the breeds were $46.57 \pm 5.99 \%$ and $20.93 \pm 2.88 \%$ respectively. While these two variables of semen cryopreserved in both the extenders were found to be slightly higher in Siri bulls than Mithun and Jersey, there was no significant difference $(p>0.05)$ between extenders and between breeds, and there was no significant effect $(p>0.05)$ of breed $\mathrm{x}$ extender interaction.

Table 2. Post-thaw motility and plasma membrane integrity of semen of different breeds of bulls cryopreserved in Tris Eggyolk Citrate and BIOXcell Extenders

\begin{tabular}{lllll}
\hline & \multicolumn{2}{c}{ Post-thaw motility (\%) } & \multicolumn{2}{c}{ Intact membrane (\%) } \\
\hline & Tris Eggyolk & BIOXcell & Tris Eggyolk & BIOXcell \\
& Citrate & & Citrate & \\
\hline Jersey & $45.50 \pm 4.38^{\mathrm{a}}$ & $45.50 \pm 5.99^{\mathrm{a}}$ & $20.15 \pm 2.32^{\mathrm{b}}$ & $20.45 \pm 2.86^{\mathrm{b}}$ \\
Mithun & $46.82 \pm 6.81^{\mathrm{a}}$ & $46.36 \pm 5.05^{\mathrm{a}}$ & $21.00 \pm 3.12^{\mathrm{b}}$ & $20.86 \pm 2.28^{\mathrm{b}}$ \\
Siri & $47.50 \pm 8.22^{\mathrm{a}}$ & $49.17 \pm 5.85^{\mathrm{a}}$ & $21.58 \pm 3.83^{\mathrm{b}}$ & $22.33 \pm 3.24^{\mathrm{b}}$ \\
\hline
\end{tabular}

Figures in main column with similar superscript show no significant difference at $\mathrm{p}>0.05$.

There was a very high correlation between post-thaw motility and plasma membrane integrity $(r=0.93), \mathrm{p}<0.01$. Although positive correlation was found between post-thaw motility and plasma membrane integrity with initial motility and livability, it was not significant $(\mathrm{p}>0.05)$.

\section{DISCUSSION}

Bos taurus and Bos indicus have several markedly different physiological and anatomical features (Felius, 1985) which could result in difference in sperm characteristics. Generally, Bos indicus bulls have a higher sperm concentration and higher sperm morphologic defects than Bos taurus (Brito et al., 2002). However, such difference is not evident in this experiment. The colour, consistency, volume, mass activity, initial motility, livability and percent of morphological abmormalities fall within the range described by Roberts (1971) and Hafez (1993). In the case of Mithun breed, while semen volume was similar to those reported by Mondal et al. (2010), it was higher than that reported by Bhattacharya et al. (2005). Sperm concentration was also found to be much higher than those reported by both Mondal et al. (2010) and Bhattacharya et al. (2005). This discrepancy could be due to the collection method employed. In regards to the semen characteristics of Siri bulls, to the knowledge of the authors, this is the first published information which should be further investigated using larger sample size and extending over different seasons.

The composition of extender and suitable cryoprotectants are important factors for successful semen cryopreservation (Hammerstedt et al., 1990; Curry et al., 1994). In this experiment, two extenders, namely, Tris eggyolk citrate and BIOXcell (a commericial soybean based extender ) were compared for the cryopreservation of semen from Jersey, Mithun Bulls and Siri bulls. Viviana et al. (2003) have reported higher sperm motility and significantly higher non return rate with Soya Lecithin based extender as compared with TRIS-EY extender. On the contrary, Thun et al. (2002) found Tris-eggyolk extender to produce the best semen quality and field fertility than Biociphos. Although, BIOXcell is fortified with antioxidants, it appears that it has no advantage over the eggyolk based extender as the natural constituent of egg yolk such as phospholipids, cholesterol and low density lipoproteins in egg yolk are equally effective in protecting the spermazoa against oxidative stress (Pace and Graham, 1974; Watson, 1976). In this study, no significant differences were found between Tris Eggyolk Citrate and BIOXcell extenders and no breed $\mathrm{x}$ extender interaction effects was also observed. This is in agreement with Hinsch et al. (1997) who found no significant differences in motility, viability, and acrosomal status of spermatozoa between soya based extenders and egg yolk-containing extenders. However, the risk of microbiological contamination and disease transmission in using eggyolk in Tris-eggyolk coupled with the 
clarity of diluted and frozen semen in BIOXcell during examination, and convenience of preparation and handling may increasingly favour the use of BIOXcell in the future.

Post-thaw motility of spermatozoa is the most widely used parameter for judging the quality of frozen semen and the potential fertility of the semen. Good progressive motility of spermatozoa is an indicator of both unimpaired metabolism and intactness of membranes (Johnson et al., 2000). An intact and functionally active membrane is essential for the spermatozoon to sustain metabolism, undergo capacitation and acrosome reaction and, further, attach to and penetrate the oocyte zona pellucida (Jeyendran et al., 1984). Positive correlation between membrane integrity assessed by fluorometric methods and fertility has been reported by Januskauskas $e t$ al. (2003). Moreover, Moreno et al. (2011) reported significant correlation between sperm with type IV and field fertility elsewhere. The HOS-EN which is a combination of the HOS test and the EN staining method described by Zhu and Liu (2000) was used for this study to categorize spermatozoa into 4 types of which type IV (White head with swollen tail) representing the viable spermatozoa with intact membrane (Moreno et al., 2011). Obtaining lower percent type IV than the post thaw motility in the present study is consistent with the finding of Zhu and Liu (2000). This could be attributed to the retention of motility by the spermatozoa with slight membrane damage. The high correlation between post-thaw motility and percent type IV spermatozoa and between membrane integrity (Januskauskas et al., 2003) and percent type IV spermatozoa (Moreno et al., 2011) and field fertility indicate the usefulness of post-thaw motility of spermatozoa as a measure of the potential fertility of the frozen semen.

The semen characteristics of Siri and Mithun bulls fall with the range established for other breeds of bulls. The semen characteristics of Siri bulls studied in this study is the first published information and should be validated with larger number of ejaculates. Since there was no significant differences between the extenders in the postthaw motility and membrane integrity, both Tris eggyolk and BIOXcell extenders could be used based on affordability. However, the conception rates after AI and fertility after long term storage in the two extenders are not known and need to be studied. There is also need to investigate and establish the optimal amount rate of glycerol addition for the cryopreservation of semen of Mithun and Siri breeds of bulls.

\section{ACKNOWLEDGEMENT}

The authors would like to express his gratitude to all the officials of National Dairy Development Centre (NDDC) particularly to Dr. Lham Tshering, Dr. Dorji and Mohan Gurung for providing unstinted assistance during the study.

\section{REFERENCE}

1. Alvarez JG and Storey BT (1992). Evidence for increased lipid peroxidative damage and loss of superoxide dismutase activity as a model of sublethal cryodamage to human sperm during cryopreservation. Journal of Andrology 13: 232- 241.

2. Amirat L, Anton M, Tainturier D, Chatagnon GR, Battut I and Courtens JL (2005). Modifications of bull spermatozoa induced by three extenders: Biociphos, low density lipoprotein and Triladyl, before, during and after freezing and thawing. Reproduction 129: 535- 543.

3. Beccaglia M, Anastasi P and Luvoni GC (2009a). Freezing of canine semen in an animal-free protein extender. Veterinary Research Community 33(Suppl 1): 77- 80.

4. Bhattacharya HK, Goswami BK, Bujarbaruah KM, Deka BC, Baishya N and Sarma BC (2005). Characteristics of semen collected by massage method in Mithun (Bos frontalis) bulls. Indian Journal of Animal Science 75: 11681169.

5. Brito LF, Silva AE, Rodrigues LH, Vieira FV, Deragon LA and Kastelic JP (2002). Effects of environmental factors, age and genotype on sperm production and semen quality in Bos indicus and Bos taurus AI bulls in Brazil. Animal Reproduction Science 15: 181-190.

6. Celeghini ECC, Arruda RPD, Andrade AFCD, Nascimento J, Raphael CF and Roderigues PHM (2008). Effects that bovine sperm cryopreservation using two different extenders has on sperm membranes and chromatin. Animal Reproduction Science 104: 119-131.

7. Curry MR, Millar JD and Watson PF (1994). Calculated optimal cooling rates for ram and human sperm cryopreservation fail to conform to empirical observations. Biology of Reproduction 51: 1014-1021. 


\section{P. Dorji and others}

8. Curry MR and Watson PF (1994). Osmotic effects on ram and human sperm membranes in relation to thawing injury. Cryobiology 31: 39-46.

9. Felius M (1985). Genus Bos: Cattle Breeds of the World, MSD-AGVET Division of Merck and Co., Rahway, p. 235.

10. Foote RH (1978). Factors influencing the quantity and quality of harvested from Bulls, Rams, Boars and stallions. Journal of Animal Science 47: 1-11.

11. Forouzanfar M, Sharafi M, Hosseini SM, Ostadhosseini S, Hajian M, Hosseini L, Abedi P, Nili, Rahmani NHR and Nasr-Esfahani MH (2010). In vitro comparison of egg yolk-based and soybean lecithin-based extenders for cryopreservation of ram semen. Theriogenology 73: 480-487.

12. Gil J, Lundeheim N, Soderquist L and Rodriguez-Martinez H (2003a). Influence of extender, temperature, and addition of glycerol on post-thaw sperm parameters in ram semen. Theriogenology 59: 1241-1255.

13. Gil J, Rodiguez-Irazoqui M, Lundeheim N, Soderquist L and Rodriguez-Martinez H (2003b). Fertility of ram semen frozen in Bioexcell and used for cervical artificial insemination. Theriogenology 59: 1157-1170.

14. Hafez ESE (1993). Reproduction in Farm Animals. $6^{\text {th }}$ edn. Philadelphia: Lea and Febiger, p. 405-439.

15. Hammerstedt RH, Graham JK and Nolan JP (1990). Cryopreservation of mammalian sperm: what we ask them to survive. Journal of Andrology 11: 73- 88.

16. Hansen GBB, Morris ID, Ersboll AK, Greve T and Christensen P (2005). DNA integrity in sexed bull sperm assessed by neutral Comet assay and sperm chromatin structure assay. Theriogenology 63: 1789-1802.

17. Henery JB (1991). Clinical Diagnosis \& Laboratory Management Methods (18 ${ }^{\text {th }}$ Edn). Sunder Co. 499-502.

18. Hinsch E, Hinsch KD, Boehm JG, Schill WB and Mueller-Schloesser F (1997). Functional parameters and fertilization success of bovine semen cryopreserved in egg yolk-containing extenders. Reproduction in Domestic Animal 32: 143-149.

19. Holt WV (2000). Basic aspects of frozen storage of semen. Animal Reproduction Science 62: 3-22.

20. Januskauskas A, Johannsson A and Rodriguez-Martinez H (2003). Subtle membrane changes in cryopreserved bull semen in relation with sperm viability, chromatin structure, and field fertility. Theriogenology 60: 743-758.

21. Jeyendran RS, Van Der Ven HH, Perezpelaez M, Carbo BG and Zanevald LJD(1984). Development of an assay to assess the functional integrity of the human sperm membrane and its relationship to other semen characteristics. Journal of Reproduction and Fertility 70: 219-228.

22. Johnson LA, Weitze KF, Fiser P and Maxwell WMC (2000). Storage of boar semen. Animal Reproduction Science 62: 143-172.

23. Mazur P (1985). Basic concepts in freezing cells In: Johnson, L.A., Larsson, K. (Eds.), Proceedings of the First International Conference on Deep Freezing of Boar Semen. Uppsala, p. 91-111.

24. Medeiros CM, Forell F, Oliveira AT and Rodrigues JL (2002). Current status of sperm cryopreservation: why isn't it better? Theriogenology 57: 327-344.

25. Meyers SA (2005). Spermatozoal response to osmotic stress. Animal Reproduction Science 89: 57-64.

26. Mondal M, Karunakaran M, Lee K and Rajkhowa C (2010). Characterization of Mithun (Bos frontalis) ejaculates and fertility of cryopreserved sperm. Animal Reproduction Science 118: 210-216.

27. Moreno A, Jorge Rubio-Guillén J, González-Villalobos D, Gutiérrez JC, Madrid-Bury N and López-Brea JJG (2011). Identification of cryodamage on plasma membrane integrity in bull spermatozoa and its relationship with field fertility. Revista Cientifica 21(5): 403 - 407.

28. Morris GJ, Faszer K, Green JE, Draper D, Grout BW and Fonseca F (2007). Rapidly cooled horse spermatozoa: loss of viability is due to osmotic imbalance during thawing, not intracellular ice formation. Theriogenology 68: 804-812.

29. Muino R, Fernandez M and Pen AI (2007). Post-thaw survival and longevity of bull spermatozoa frozen with an egg yolk-based or two egg yolk-free extenders after an equilibration period of $18 \mathrm{~h}$. Reproduction in Domestic Animal 42: 305-311.

30. Pace MM and Graham EF (1974). The components in egg yolk which protect bovine spermatozoa during freezing. Journal of Animal Science 39: 1144-1149.

31. Parks JE and Graham JK (1992). Effects of cryopreservation procedures on sperm membranes. Theriogenology 38: 209-222.

32. Roberts SJ (1971). Veterinary Obstetrics and Genital Disease. 2nd edn, Indian: CBS publishers and Distributors, p. 612-750.

33. Salamon S and Maxwell WM (2000). Storage of ram semen. Animal Reproduction Science 62: 77-111.

34. Stradaioli G, Noro T, Sylla L and Monaci M (2007). Decrease in glutathione (GSH) content in bovine sperm after cryopreservation: Comparison between two extenders. Theriogenology 67: 1249-1255. 


\section{Cryopreservation of semen of mithun and siri bulls}

35. Thun R, Hurtado M and Janett F (2002). Comparison of Biociphos-Plus ${ }^{\circledR}$ and Tris-egg yolk extender for cryopreservation of bull semen. Theriogenology 57: 1087-1094.

36. Vishwanath R and Shannon P (2000). Storage of bovine semen in liquid and frozen state. Animal Reproduction Science 62: 23-53.

37. Viviana AA, Hinsch KD, Mueller-Schloesser KS, Bogner F, Mueller-Schloesser S and Hinsch E (2003). In vitro and in vivo comparison of egg yolk based and soybean lecithin-based extenders for cryopreservation of bovine semen. Theriogenology 60: 269-279.

38. Watson PF (1976). The protection of ram and bull spermatozoa bye the low density lipoprotein fraction of egg yolk during storage at $5^{\circ} \mathrm{C}$ and deep freezing. Jorunal of Thermal Biology1: 137-141.

39. Watson PF (2000). The causes of reduced fertility with cryopreserved semen. Animal Reproduction Science 60-61: 481-492.

40. Woelders H (1997). Fundamentals and recent development in cryopreservation of bull and boar semen. Veterinary Quarterly 19: 135-138.

41. Zhu WJ and Liu XG (2000). Cryodamage to plasma membrane integrity in head and tail regions of human sperm. Asian Journal of Andrology 2(2): 135-138. 